\title{
РЕГИОНАЛЬНАЯ КУЛЬТУРА: СУБЪЕКТНО-ОБЪЕКТНЫЕ ВЗАИМОДЕЙСТВИЯ В СФЕРЕ УПРАВЛЕНИЯ (НА ПРИМЕРЕ КУРСКОЙ ОБЛАСТИ)
}

\author{
Андриянова Татьяна Владимировна, \\ andriyanova.tv@gmail.com \\ Курский государственный университет, \\ Россия, 305004, г. Курск, ул. Радищева, 29.
}

\begin{abstract}
Андриянова Татьяна Владимировна, кандидат социологических наук, доцент кафедры социологии Курского государственного университета.
\end{abstract}

\begin{abstract}
Актуальность исследования определяется необходимостью выработки новых моделей в сфере управленческих практик в поле региональной культуры, учитывающих не только проблему сохранения традиционной культуры, но и потребности самоорганизации разных групп населения, формирования их активности и интерсубъектности. Объектом выступает региональная культура в разрезе взаимодействия руководителей культурно-досуговых учреждений с населением. Предметом исследования являются субъектно-объектные отношения, складывающиеся в поле управления региональной культурой. Цель работы заключается в оценке эффективности функционирования представленной субъектно-объектной модели изучения региональной культуры в сфере управления, что позволило выявить механизмы типизации культурного опыта, формирования «мы-групп» и «общего социального наследия». Методология основывается на феноменологической исследовательской парадигме, «Модельном стандарте деятельности культурно-досуговых учреждений», статистических данных, неструктурированных интервью руководителей и представителей власти Курской области, формировании развернутого представления о повседневных практиках взаимодействия руководителей и населения в структуре региональной культуры. Выводы: субъектнообъектная модель изучения региональной культуры позволяет атрибутировать повседневные практики взаимодействия руководителей и населения как самоорганизующиеся, основанные на механизмах усвоения традиционной культуры с интерсубъектной ориентацией.
\end{abstract}

Ключевые слова: Региональная культура, субъектно-объектные отношения, культурно-досуговые учреждения культуры, руководители, повседневность.

\section{Введение}

В 2006 г. на одном из заседаний Государственного совета рассматривался вопрос государственной поддержки традиционной народной культуры и Президент России В.В. Путин отметил: «Для нашей многонациональной страны разнообразие народного творчества, обрядов, обычаев, ремёсел - не только бесценное наследие. Это наше общенациональное преимущество. Ведь культура народов России выполняет в обществе ключевую объединяющую роль, способствует сближению и взаимопониманию между людьми, утверждению принципов согласия и толерантности» [1]. Особую актуальность приобретает вышесказанное ещё и потому, что в Российской Федерации 2020 г. объявлен тематическим Годом народного творчества. От того, насколько чётко будет определена региональная культурная политика в соответствии с современными требованиями и тенденциями прогрессивного развития отрасли, зависит достижение целевых показателей Национального проекта «Культура», принятого в 2018 г.: 
- увеличение числа посещений организаций культуры должно вырасти к 2024 г. на $15 \%$;

- увеличение числа обращений к цифровым ресурсам в сфере культуры должно вырасти к 2024 г. до 80 млн [2].

Региональная культура - это неисчерпаемое поле для осмысления и развития. Известно, что она никогда не имела того отдельного статуса и пафосного значения, которым обладали культура столичных и областных центров. Однако текст этой культуры вплетён в ткань региональной истории ещё плотнее и естественнее, чем это можно наблюдать на уровне глобальной истории страны. Региональная культура приобретает полноценное содержание и смысл, перестаёт быть второсортной копией «общекультурного» процесса. Вопросы современного развития касаются того, как аутентичное сделать актуальным и увлекательным для современного жителя, включая и горожанина? Как наука и практика решают задачи вместе по продвижению и обмену знаниями о нематериальном наследии региона? Как по-новому говорить подрастающему поколению о сохранении традиции, его региональном своеобразии? Однозначных ответов пока нет. Точки соприкосновения между новыми веяниями современности и традиционной «архаичностью» находятся в апробации различных проектов, форм и методов деятельности учреждений культуры различного типа, которые оказывают значительное влияние на общности в их культурном развитии и большей информированности.

\section{Теоретико-методологические подходы}

Культурологический подход описывает формирование региональной культуры как «длительный процесс выработки ее специфики, с одной стороны, органично связанной с особенностями «материнской культуры», а с другой стороны, сформировавшейся в конкретных исторических условиях и отражающих эти условия» [3, с. 84]. При этом отмечается, что региональная культура не может быть полностью редуцирована по отношению к «материнской культуре» и представляет собой относительно самостоятельное явление, определяющую роль в котором играет «раскрытие внутреннего содержания региональной культуры» [3, с. 84]. О.Б. Фоминых дает определение региональной культуры как специфического социокультурного образования, характеризующегося не только внешними признаками (пространственная локализация, территориальная соотнесенность с ядром национальной культуры), но и внутренними особенностями (локальные традиции, система ценностей, специфика мировосприятия, осознание своей принадлежности к региональному сообществу, восприятие территории как необходимого условия существования этого сообщества, выработка специфического, регионального культурного стиля и/или формирование специфически местных видов искусства и народного, художественного творчества) [3]. По мнению С.И. Петровой, «управленческая активность в динамике культуры отражается через сферы научнопознавательной, информационной деятельности и традиционного менеджмента» [4, с. 134]. А функционирование социальных институтов, общественных организаций и норм различных видов деятельности рассматривается сразу в нескольких областях знания - социологии, социальной антропологии и этике [4].

Философский подход определяет регионализм как феномен, задающий специфику развития современного социокультурного пространства. И.В. Карандашов, проводя анализ понятий «регион» и «региональная культура», приходит к выводу, что «регион как социокультурное пространство играет стратегически значимую роль в современном динамично развивающемся трансформирующемся обществе, определяя возможности расширения пространств коммуникации, понимания, социального творчества и управ- 
ления» [5]. Вместе с тем И.Ф. Петров считает, что региональную культуру следует рассматривать как субкультуру, так как она хотя и обусловлена уровнем культуры всей страны, при этом существуют и уникальные особенности территорий [6]. Автор выделяет следующие системообразующие факторы региональной культуры:

- развитое региональное самосознание;

- региональные культурные интересы;

- общий исторический и культурный опыт;

- структура и этнонациональный состав населения;

- социально-экономические различия;

- наличие региональных «агентов» формирования региональной культуры;

- межрегиональные и международные связи;

- своеобразие природных условий региона.

Культурно-географический подход в региональных исследованиях обосновывается В.Н. Стрелецким с выходом на двуединую трактовку понятия «регионализм» как феномена культуры в его онтологических и перцепционных характеристиках: объективная основа и субъективный, перцепционный «слой». Эти пласты (грани) тесно взаимосвязаны, но они разные и их в мировоззренческом и методологическом отношении важно разграничивать. Культурная самобытность территории, в пределах которой сложилось местное сообщество людей с особыми интересами, системами ценностей и типом ментальности, может в разной степени осознаваться самими представителями данной общности [7]. Автором предложены и рассмотрены основные индикаторы культурного регионализма: региональное самосознание, этническая гомогенность или гетерогенность, поселенческая структура, особенности природопользования и способы ведения хозяйства, местная языковая система, конфессиональная структура, сфера ментифактов (духовные традиции, образы), материальная культура, паттерны и стереотипы усвоенного поведения.

В зарубежных исследованиях в качестве основного понятия выступает «регионализм» в рамках социально-политического поля. Так, Б. Хеттне [8] под регионализмом понимает политические движения в рамках разных региональных сообществ, направленные на обретение институционального статуса (борьба за политическую или культурную автономию, за самоуправление провинций, этнических или территориальных групп людей) либо на расширение уже существующих прав региональных сообществ. В классификации П. Шмитт-Эгнера в качестве отдельных типов выделяются: так называемый «старый» регионализм (на первый план выдвигаются задачи политического самоопределения регионов); «новый» регионализм (движения за децентрализацию регионализацию и автономизацию - внутри страны); «постмодернистский» регионализм (не связанный с выдвижением территориальных политических требований, но преследующий цели формирования позитивного имиджа региона как ключевого условия повышения его конкурентоспособности в разных сферах общественной жизни); «транснациональный» регионализм (достижение региональных эффектов за счёт внешнего - трансграничного и межрегионального - сотрудничества); «межгосударственный» регионализм (участие национальных государств в качестве макрорегиональных акторов). Шмит-Эгнер дал наиболее фундаментальное и общее социогуманитарное определение понятия «регион» как пространственной парциальной единицы среднего размера посреднического характера, чей материальный субстрат основывается на территории [9]. Ряд зарубежных авторов сходятся во мнении, что регион - однородное пространство с физическими и культурными характеристиками, отличающимися от таковых соседних пространств. Ключевым элементом является определенная социальная 
гомогенность [10]. Существуют различные подходы и к определению региональной интеграции. К примеру, Эндрю Хуррел перечисляет пять качественных характеристик интеграции: а) регионализация; б) региональное сознание и идентичность; в) региональное межгосударственное взаимодействие; г) санкционированная государством региональная интеграция; д) региональное единство [11].

Социологический подход к исследованию культуры в данной работе базируется на феноменологической парадигме, которую представляют А. Щюц, Т. Лукман, П. Бергер. Они рассматривают социальное взаимодействие как процесс координации поступков людей, наделяющих действия друг друга смыслом, типичным для жизненного опыта. Общность и устойчивость смыслов, придаваемых ситуациям взаимодействия, упорядочивают эти ситуации и превращают их в объективную реальность - социальные феномены. Таким образом, социальная реальность конструируется, хотя большей частью непреднамеренно и привычно для участников взаимодействия.

А. Шюц, основываясь на идеях Э. Гуссерля и М. Вебера, разрабатывает собственную концепцию, развивающую идеи понимающей социологии и теории социального действия, но в несколько другом ракурсе. Давая определение социальной реальности как совокупности «объектов и событий внутри социокультурного мира как опыта обыденного сознания людей, живущих своей повседневной жизнью среди себе подобных и связанных с ними разнообразными отношениями интеракции» [12], А. Щюц отмечает, что это мир культурных объектов и социальных институтов, в котором человек рождается, находит точку опоры и налаживает взаимодействия. Мир предстает перед ним как интерсубъективный мир культуры, общий для всех, актуальный и доступный каждому, на основе чего формируются интеркоммуникация и язык. Процесс взаимодействия приводит к наделению всех вещей социальным смыслом, в том числе и тех, которые способствуют возникновению и поддержанию социальной организации, включая духовные образования.

Однако сконструированный социальный порядок в силу естественной установки сознания воспринимается индивидами как объективная реальность - система норм и правил, которые необходимо усвоить и которым необходимо следовать. Эту двойственность общества, представляющего собой одновременно и «субъективные смыслы», и «объективную фактичность» проанализировали П. Бергер и Т. Лукман [13] в совместной работе «Социальное конструирование реальности». Типизации повседневной жизни образуют социальные конструкты первого порядка, на их основе возникли конструкты второго порядка, формирующие «конечные миры смыслов» - науку, религию, искусство, экономику, сны и т. д.

Феноменологическая социология хорошо описывает и объясняет то, как люди взаимодействуют в повседневной жизни, и в отличие от символического интеракционизма уделяет большое внимание социальным структурам. Однако обе эти парадигмы недооценивают роль неравенства и конфликтов в процессах социального взаимодействия и управления.

\section{«Субъектно-объектная» модель исследования региональной культуры}

В статье автором предлагается феноменологический подход в качестве основы субъектно-объектной модели исследования региональной культуры. Он помогает раскрыть динамику человеческих представлений от индивидуального к универсальному, т. к. именно на основе субъективного опыта происходит процесс становления объективного. А. Щюц описывает объективацию на основе механизмов идеализации и типизации, когда человек имеет представление не о разрозненной картине мира, а стройной системе 
объектов, объединенных в классы. Вместе с тем внутри классов существуют и различия в объектах, что также понимается как апперцептивный перенос отдельных черт объекта на любой другой сходный объект, т. е. как типизация. Реальный опыт подсказывает, существуют или нет эти типические соответствия. Если да, то класс объектов разбивается на подклассы (типы). Поскольку повседневное знание носит социальный характер, Шюц выделяет и механизмы интерсубъектности, переводящие индивидуальное в ранг общезначимого. Здесь необходимо остановиться на механизме «взаимности перспектив», при анализе которого важным выводом становится тезис о том, что общезначимое существует только в границах определенной группы («мы-группы»), члены которой разделяют индивидуальную систему релевантностей, построенную на ценностях общей для них культуры. А. Шюц определяет это как «общее социальное наследие» [14].

С точки зрения формирования управленческого контекста исследования и для структурирования полученных эмпирических данных в контексте данной модели автор использует «Модельный стандарт деятельности культурно-досугового учреждения» (далее - Стандарт), разработанный для регионов РФ на основе действующих нормативных правовых актов, методических рекомендаций Министерства культуры РФ и с учетом специфики организации сети учреждений культурно-досугового типа области. В нем достаточно четко прослеживаются пути взаимодействия между самим учреждением культуры и потребителями его услуг (различными группами населения). Анализируя реальные показатели деятельности региональных учреждений культуры и тексты интервью их руководителей, можно определить, насколько эффективно складывается эта система взаимодействия и в чем ее управленческий потенциал [15].

В качестве основных определений Стандарта автор использует следующие: «культурно-досуговая деятельность», «культурно-досуговое учреждение», «клубное формирование», «коллектив любительского художественного творчества», «норма обслуживания» [16]. В общей сложности насчитывается восемь различных видов культурно-досуговых учреждений, в том числе стационарные и передвижные, каждому из которых определены соответствующие цели, задачи и виды деятельности [17]. В перечень услуг, предоставляемых населению культурно-досуговым учреждением, входит 29 наименований, причем каждое учреждение вправе самостоятельно определяет перечень своих услуг согласно своей миссии и решаемым задачам [18]. Они имеют интегрированный характер и могут представляться в различной форме (массовой, камерной, индивидуальной, интерактивной) и на любой демонстрационной площадке (в зрительном, танцевальном, выставочном зале, на площади, стадионе, в учебном заведении и т. д.). В качестве основных субъектов-потребителей услуг культурно-досугового учреждения могут выступать органы государственной власти и местного самоуправления, юридические лица и физические лица. Среди факторов доступности культурно-досуговых услуг для всех групп населения на первое место выходит рациональное размещение сети культурно-досуговых учреждений, учитывающее социальные нормы и нормативы обеспеченности населения культурно-досуговыми учреждениями [19].

\section{Результаты исследования и их обсуждение}

В исследованиях 2004 г. автор показал, что «для эффективного осуществления своей основной деятельности учреждения культуры должны активно стремиться к систематическим неформальным контактам с аудиторией. Этому способствует объединение различных организаций в рамках одного территориально-пространственного или архитектурного комплекса» [20]. С одной стороны, это отражает динамику текущей ситуации с культурно-досуговыми организациями: 
- в 2004 г. в Курской области количество клубов сократилось на 145, что составляло $13,2 \%$ от их общего числа;

- в 2019 г. в процессе оптимизации и административных реформ по укрупнению территорий сельских советов эта цифра достигла $21 \%$, а в целом по стране $-50 \%$.

С другой стороны, это требует осмысления на уровне субъектно-объектных отношений, т. к. более 6,5 млн человек в стране - это участники любительских объединений (в нашем регионе - более 63 тысяч, а это практически каждый пятый житель сельской местности).

Основываясь на субъектно-объектной модели, приведем результаты исследования 2019 г. по учреждениям культурно-досугового типа, наиболее распространенным в сельской местности. В него вошли неструктурированные интервью руководителей учреждений культуры и представителей власти Курской области $(N=14)$, анализ статистической информации и реальные показатели деятельности [21].

По своему типу это некоммерческие организации, основным видом деятельности которых является предоставление населению разнообразных услуг социальнокультурного, информационно-просветительского, оздоровительного и развлекательного характера, создание условий для занятий любительским художественным творчеством. В Курской области действуют 694 учреждения культурно-досугового типа, в которых работают 1938 специалистов. Общий процент специалистов с профильным образованием составляет 81,5 \%. Они обеспечивают всем группам населения конституционные права на доступ к культурным благам по трём стержневым направлениям деятельности:

- сохранение нематериального культурного наследия и популяризация традиционной народной культуры в соответствии со Стратегией национальной безопасности Российской Федерации, утверждённой Указом Президента РФ от 31.12.2015 г. № 683 [22], где данный процесс зафиксирован как национальный интерес на долгосрочную перспективу;

- активизация культурно-просветительской деятельности в социуме, включая организацию досуга всех категорий населения;

- развитие любительского народного творчества.

Останавливаясь подробнее на вышеозначенных пунктах, можно отметить следующее. Во-первых, исключительно в сельской местности живут истинные носители народной культуры, ее генетического ресурса, творцы и хранители сокровищницы нематериального и материального культурного наследия. Поэтому, несмотря на сближение интересов различных социальных слоёв граждан, особенно в сельской местности, естественным социальным регулятором по-прежнему являются обычаи и традиции, негласные правила бытия, опирающиеся на этнические культурные особенности. Отчего любые негативные явления в обществе могут преодолеваться за счёт сохранения и развития традиционной культуры, препятствующей проникновению прагматических ценностей, разрушению нравственных устоев, социальных и культурных связей. Вовторых, технологии деятельности учреждений клубного типа сегодня позволяют населению активно осваивать культурные ценности путём непосредственного включения в творческий процесс, в процесс подготовки и проведения массовых культурных акций. Просветительский и педагогический эффект таких технологий очевиден. Поставленная задача стимулирования самоорганизации культурной жизни граждан выдвигает на первый план укрепление методической службы, которая наряду с помощью берёт на себя функцию координации деятельности культурно-досуговых учреждений региона. В Курской области ОБУК «Курский дом народного творчества» проводит мониторин- 
говые исследования по определению удовлетворённости населения качеством предоставляемых услуг в сфере культуры. Их результаты говорят о том, что большая часть культурно-досуговых учреждений региона готова предлагать новые виды услуг, в частности на стыке образовательных и культурно-просветительных. Например, внедрение инновационно-экспериментальных проектов:

- по брендированию территорий «Край мой - капелька России», возрождению деревенских праздников «Глубинкою жива Россия», объединяющих годовой календарный цикл;

- по активизации досуговой деятельности, основанной на этническом колорите местности «Живая нить традиций», способствующей возникновению новых форматов проведения мероприятий;

- по содействию новым клубным формированиям и вовлечению различных групп населения в организованные формы досуговой деятельности путем организации смотра-конкурса «Отдых. Творчество. Досуг».

В целом, всё это способствует активизации культурного потенциала особенно в сельских поселениях.

В-третьих, народное творчество является рельефно выраженным самосознанием народа, через которое происходит укрепление нравственных ценностей. Неотъемлемой частью огромного пласта под названием «народное творчество» была и остаётся художественная самодеятельность - уникальное явление, родившееся творческой инициативой масс ещё на заре XX в. и не имеющее мировых аналогов. Она подразумевает не столько зрительское восприятие художественных ценностей, сколько возможности вовлечения населения в процесс освоения различных видов искусства. Участники этих процессов не просто фиксируют события, а часто являются творцами, создателями любительских художественных произведений. Для развития жанров самодеятельного творчества в регионе проводятся самые различные фестивали-конкурсы: «Созвездие молодых», «Память сердца», «Курская рампа», «Соловушка», «Куклы говорят», «Сударушка», «Мы славим тебя, Россия!», «Курский каблучок», «Серебряные трубы», «Курские зори» с участием населения всех возрастных категорий. Несколько десятилетий проводятся социально значимые всероссийские фестивали-конкурсы «Солнце России» и «Дёжкин карагод» имени Надежды Плевицкой, получившие широкое признание за пределами нашей страны. Инициирован в новом формате областной конкурс «Соловушка» среди детских и молодёжных творческих коллективов этнографического, стилизованного и этно-футуристического направлений. Активно внедряются самобытные обрядовые праздники, основанные на этнокультурных традициях и особенностях местных сообществ (например, «Левада», «Батюшка Егорий», «Псёлский разгуляй»), что способствует развитию событийного туризма. Реализуются различные проекты по поддержке народных промыслов и ремёсел: межрегиональные фестивали-конкурсы «Мастера в соловьином крае» и «Заиграй, моя игрушечка», мастер-классы по освоению различных ремесленнических навыков в филиалах Дома народного творчества и выставочном зале «Курские промыслы и ремёсла». Издаются иллюстрированные сборники о мастерах декоративно-прикладного творчества. Вводятся меры по сохранению и популяризации культуры казачества на территории его исконного бытования. Варианты подобной практики в той или иной степени внедряются и в муниципальных учреждениях культурно-досугового типа области с учётом местной специфики и локальных особенностей.

В рейтинге по количественному показателю коллективов самодеятельного творчества Курской области первенство держит хореографический жанр, который пред- 
ставляют 465 коллективов с общим числом участников почти 7,5 тысяч человек. Немногим уступает по количеству коллективов (430 с числом участников около 5 тысяч человек) театральный жанр, который представлен самыми различными видами: драматический и музыкально-драматический, театр кукол, театр эстрадных миниатюр и экспресс-театр, ТЮЗ, театр теней и др. Развивается вокально-хоровой жанр и в настоящее время: в культурно-досуговых учреждениях области действует 411 коллективов, объединяющих более 5,5 тысяч участников. В числе аутсайдеров инструментальный жанр - всего 44 коллектива по области, поскольку не каждое муниципальное учреждение культуры может позволить себе приобретение дорогостоящих духовых, струнных, язычковых и ударно-клавишных музыкальных инструментов. Практически все эти творческие коллективы сформировались ещё в 70-80-е годы прошлого столетия, тогда же и приобретались музыкальные инструменты. Именно творческие коллективы любой жанровой направленности, любительские объединения общественного или познавательного характера создают основу практически всех клубных мероприятий. Главное сегодня - вернуться к осознанию, что их главной функцией является просветительская и воспитательная, а не развлекательная. Поэтому современная модель Дома культуры это единый культурный оазис сельского поселения, центр общения и притяжения, куда придут дети и целые семьи, жители разных возрастов и социальных предпочтений.

Проблемы, на которые указывали в своих интервью руководители, возникают с учетом того, что в ближайшие шесть лет нужно максимально выполнить Указ Президента Российской Федерации от 07.05.2018 г. № 204 «О национальных целях и стратегических задачах развития Российской Федерации на период до 2024 года» [23], где ставятся задачи взаимодействия власти и населения. Еще одна проблема появилась вследствие оптимизации при исполнении Указа Президента Российской Федерации от 7 мая 2012 г. № 597 «О мероприятиях по реализации государственной социальной политики» [24]. В погоне за выполнением показателя средней заработной платы ставки работающих в сельских культурно-досуговых учреждениях и библиотеках снижены до 0,3-0,5 ставки. Подходить к этому вопросу нужно дифференцированно, учитывая особенности местности и количество населения и приводя штатные расписания в соответствие.

Из интервью с начальником Управления культуры, молодежной политики, физической культуры и спорта администрации Обоянского района: «B настоящее время работать в сельской местности становится все сложнее. Связано это с оттоком людей из глубинки и естественным убыванием населения. Но задача по сохранению местных традиций, фольклорных коллективов, промыслов, ремесел и обычаев поставлена, а вот накопленный опыт зачастую передавать уже некому. Бывают случаи, когда невозможно найти работника на должность директора клуба или заведующего библиотекой. Сегодня требуются специиалисты только с образованием, а учиться не все хотят. Необходимо, наверное, более активно привлекать в нашу сферу детей и молодежь. В качестве положительного приведу пример, когда в намем районе в последние годы ежемесячно проходят семинарские занятия с творческими отчетами по всем клубным формированиям в сельских учреждениях культуры с приглашением всех работников досуговой сферы. На этих кониертах мы обращаем внимание в первую очередь не на то, как поет или таниует директор или художественный руководитель, $а$ на то, как ведется работа по привлечению в творческий прочесс населения. С каждым годом качество кониертных программ улучшается, так как присутствует соревновательный процесс между всеми клубами и повышается мера ответственности, а у работников есть стремление выглядеть на уровне коллег». 
Из интервью с директором ОБУК «Курский Дом народного творчества»: «Нашим учреждением ведётся работа по включению самобытных явлений культурного наследия Курской области в Единый электронный каталог объектов нематериального культурного наследия России. На сегодняшний день на сайте «Культура РФ» уже опубликовано 9 объектов наследия, характеризующие местные исполнительские традиции, календарные и семейно-бытовые обряды, ремесленные технологии. Организовываются этнографические экспедичии с дальнейшей расшифровкой уникального материала, издаются сборники "Фольклорная тетрадь», популяризирующие неповторимые особенности локальной курской музыкально-певческой традциии как части российской культуры. Осуществляется методическая и практическая помощь фольклорным коллективам, которых в области насчитывается 153, из них в сельской местности $-117 »$.

Из интервью с директором ОБУК «Драматический театр им. А.С. Пушкина»: «Несмотря на доступную ценовую политику, спектакли нашего театра могут посетить не все жители Курской области ввиду своей удаленности. Поэтому курский драмтеатр осуществляет выезды в сельские дома культуры с иелью пропаганды, а для некоторых и знакомства впервые, с театральным драматическим искусством. На местах театр сталкивается с проблемой несоответствия площадки сельского дома культуры минимальным требованиям показа спектакля. Поэтому выезжают к сельскому зрителю спектакли малой формы с минимальным количеством актеров».

В настоящее время для создания условий для творческой работы в сельских учреждениях культуры время есть поддержка в рамках Федерального проекта партии «Единая Россия» «Культура малой Родины» по направлению «Местный дом культуры» [25]. Это хорошая помощь учреждениям культуры, но данный проект не предполагает ни ремонтов, ни газификации, а прежде чем покупать аппаратуру, инструменты, шить одежду или покупать кресла, нужно, чтобы людям хотелось идти в красивое, уютное учреждение культуры с целью провести свой досуг. В регионе есть сельские дома культуры, которые до сих пор не отапливаются и требуют ремонта. Если их нужно сохранить, то необходимо что-то менять в этом направлении, создавая, может быть, и новые проекты на уровне области. Например, в 2019 г. Чекмаревский сельский клуб Обоянского района, находившийся в аварийном состоянии восемь лет, получил средства на реконструкцию в рамках реализации Государственной программы Российской Федерации «Развитие культуры и туризма» на 2013-2020 гг. [26].

В целом все руководители в своих интервью отметили заметный рост в последние годы заинтересованности населения в реализации творческих способностей. В современных условиях любой гражданин всё более стремится к самореализации своих личностных способностей. Важно, что и молодое поколение осознаёт тот факт, что личная активность, связанная с преобразованиями окружающего мира и творчеством, является базовым условием для будущего развития. Единственным подчас «поставщиком» культурным благ для миллионов жителей российской провинции остаются муниципальные учреждения культуры, которые по-прежнему составляют 90 \% от всей клубной сети в стране (в Курской области этот показатель ещё выше - 96,2 \%) и являются проводниками культуры для населения. Главной миссией этих учреждений в любом регионе являются осуществление деятельности по формированию единого культурного пространства на территории субъекта и содействию в развитии созидательной инициативы населения, художественного разножанрового творчества и любительского искусства, объединение усилий учреждений культуры всех форм собственности. Руководители, опираясь на свой опыт работы, высказались в пользу совместного создания условий для 
качественного изменения отрасли при поддержке региональной власти и необходимости следующих управленческих действий:

- продолжить продуктивную практику по проведению областных, всероссийских и международных фестивалей-конкурсов по различным видам и жанрам искусства для стимулирования и активизации культурной жизни региона, расширению контактов с субъектами страны и зарубежья, формированию благоприятного имиджа Курской области;

- расширить тематический спектр выделения региональных грантов на реализацию творческих проектов;

- повысить роль программного финансирования значимым проектам в области культурно-досуговой деятельности, народного творчества и традиционной культуры;

- содействовать молодым специалистам, прибывшим на работу в сельские учреждения культуры, в решении вопросов приобретения или получения жилья.

- сформировать собственный региональный электронный каталог объектов нематериального культурного наследия Курской области.

\section{Выводы}

1. Объективация в сфере региональной культуры реализуется в основном на основе механизмов идеализации и типизации. В первом случае имеется широко распространенная в сельской местности традиционная культура, носителями, хранителями и «передатчиками» которой служат сами люди, воспринимающие ее как идеальную картину жизненного мира в объектах разного типа. Во втором случае эти объекты имеют свои индивидуальные черты, которые апперцептивно переносятся на классы других объектов и, в свою очередь, типизируются и разбиваются на подклассы.

2. Фундамент развития региональной культуры образуют различные практики самоорганизации населения, особенно в области любительского творчества в сельской местности, позволяющие выделять в них интерсубъектность как основную социальную характеристику.

3. Если говорить об обозначенном способе «взаимности перспектив» в организации жизненного мира, то при его анализе на материалах региональной культуры становится ясной та система релевантностей для «мы-группы» каждого поселения и региона в целом, которую А. Шюц определяет как «общее социальное наследие».

4. Управленческие решения, принимаемые на основе выработанных норм и правил не всегда соответствуют процессам трансформации общества и могут быть верифицированы за счет использования более гибких социальных технологий.

\section{СПИСОК ЛИТЕРАТУРЫ}

1. Стенографический отчет о заседании Государственного совета «О государственной поддержке традиционной народной культуры в России». URL: http://kremlin.ru/events/president/transcripts/23986 (дата обращения 10.10.2019).

2. Национальный проект «Культура»: планы и направления. URL: https://www.mkrf.ru/press/news/ natsionalnyy_proekt_kultura_plany_i_napravleniya/ (дата обращения 28.09.2019).

3. Фоминых О.Б. Региональная и провинциальная культура: некоторые характеристики // Время культуры в региональном пространстве: сборник научных трудов / под ред. Д.Н. Маслюженко. - Курган, 2010. - С. 74-84.

4. Петрова С.И. Культурные системы и их взаимодействие // Инновационное развитие. -2017. - № 4 (9). - С. 132-134.

5. Карандашов И.В. Регионализм в современном социокультурном контексте // Гуманитарные научные исследования. - 2016. - № 6. URL: http://human.snauka.ru/2016/06/15686 (дата обращения 27.09.2019).

6. Петров И.Ф. Региональная культура как специфическая форма существования социума // International Journal of Humanities and Natural Sciences. - 2018. - Vol. 7. - C. 24-27. URL: 
https://cyberleninka.ru/article/n/regionalnaya-kultura-kak-spetsificheskaya-forma-suschestvovaniyasotsiuma (дата обращения 10.10.2019).

7. Стрелецкий В.Н. Культурный регионализм: сущность понятия, проблемы изучения и система индикаторов // Псковский регионологический журнал. - 2012. - № 14. - С. 9-21.

8. Hettne B. Globalization and the new regionalism: the second great transformation // Eds. B. Hettne, A. Inotai, O. Sunkel // Globalism and the New Regionalism. - London: Palgrave Macmillan, 1999. - P. 3-24.

9. Schmitt-Egner P. The concept of «region»: theoretical and methodological notes on its reconstruction // European Integration. - 2002. - V. 24. - № 3. - P. 179-200.

10. Sehgal S. The evolution of NAFTA. An Experience in Regionalism // India Quarterly: a Journal of International Affairs. - 2010. - V. 66. - № 3. - P. 303-305.

11. Fawcett L., Hurrell A. Regionalism in the world politics: regional organization and international order. Oxford: Oxford University Press, 1995. - 342 p.

12. Schutz A. The phenomenology of the social world. - London: Heinemann educational books, 1972. $-255 \mathrm{p}$.

13. Berger P.L., Luckmann Th. The social construction of reality: a treatise in the sociology of knowledge. URL: http://www.perflensburg.se/Berger\%20social-construction-of-reality.pdf (дата обращения 27.09.2019).

14. Schutz A. On phenomenology and social relations: selected writings. - Chicago: University of Chicago Press, 1970. - 327 p.

15. Модельный стандарт деятельности учреждения культурно-досугового типа Тверской области. URL: http://reftop.ru/modelenij-standart-deyatelenosti-uchrejdeniya-kuleturno-dosugo.html (дата обращения 10.10.2019).

16. О введении в действие методических рекомендаций субъектам Российской Федерации и органам местного самоуправления по развитию сети организаций культуры и обеспеченности населения услугами организаций культуры: распоряжение Министерства культуры Российской Федерации от 02.08.2017 № P-965. URL: http://docs.cntd.ru/document/456084648 (дата обращения 10.10.2019).

17. Об утверждении Методических указаний по реализации вопросов местного значения в сфере культуры городских и сельских поселений, муниципальных районов и Методических рекомендаций по созданию условий для развития местного традиционного народного художественного творчества: приказ Министерства культуры и массовых коммуникаций РФ от 25.05.2006 г. № 229. URL: http://base.garant.ru/192873/\#ixzz63MYILa4x (дата обращения 10.10.2019).

18. Об утверждении номенклатуры государственных и муниципальных услуг/работ, выполняемых организациями культурно-досугового типа Российской Федерации: распоряжение Министерства культуры РФ от 18.09.2009 № P-6. URL: http://base.garant.ru/55170135/\#ixzz63Mcvyu6J (дата обращения 10.10.2019).

19. Об утверждении нормативов минимального ресурсного обеспечения услуг сельских учреждений культуры (общедоступных библиотек и культурно-досуговых учреждений): приказ Министерства культуры РФ от 20.02.2008 № 32. URL: http://docs.cntd.ru/document/902113553 (дата обращения 10.10.2019).

20. Безуглова Т.В. Новые формы развития учреждения культуры. Комплексные культурные центры в сельской местности // Справочник руководителя учреждения культуры. - 2004. - № 9. - С. 64-67.

21. Андриянова Т.В. «Паспорт культурной жизни» региона как инструмент сравнительного анализа показателей // Актуальные проблемы развития человеческого потенциала в современном обществе: материалы V международной научно-практической конференции (5-6 декабря 2018 г.). - Пермь: Перм. гос. нац. исслед. ун-т, 2018. - С. 172-182. URL: https://elis.psu.ru/node/555431 (дата обращения 10.10.2019).

22. О Стратегии национальной безопасности Российской Федерации: указ Президента РФ от 31.12 .2015 № 683. URL: http://www.consultant.ru/document/cons_doc_LAW_191669/ (дата обращения 10.10.2019).

23. О национальных целях и стратегических задачах развития Российской Федерации на период до 2024 года: указ Президента Российской Федерации от 07.05.2018 г. № 204 . URL: http://kremlin.ru/acts/bank/43027 (дата обращения 10.10.2019).

24. О мероприятиях по реализации государственной социальной политики: указ Президента Российской Федерации от 07.05. 2012 г. № 597. URL: http://base.garant.ru/70170950/ (дата обращения 10.10.2019).

25. Культура малой Родины. URL: https://er.ru/projects/kultura-maloi-rodiny/ (дата обращения 10.10.2019).

26. Государственная программа Российской Федерации «Развитие культуры и туризма на 2013-2020 годы». URL: https://www.russiatourism.ru/contents/deyatelnost/programmy-i-proekty/gosudarstvennaya-programmarossiyskoy-federatsii-razvitie-kultury-i-turizma-na-2013-2020-gody/1/ (дата обращения 10.10.2019).

Поступила 14.10.2019 г.. 
UDC 316.73:394(470.323)

\title{
REGIONAL CULTURE: SUBJECT-OBJECT INTERACTIONS IN THE FIELD OF MANAGEMENT (ON THE EXAMPLE OF KURSK REGION)
}

\author{
Tatiana V. Andriyanova, \\ andriyanova.tv@gmail.com \\ Kursk State University, \\ 29, Radishchev street, Kursk, 305004, Russia.
}

Tatiana V. Andriyanova, Cand. Sc., associate professor, Kursk State University.

The relevance of the study is determined by the need to develop new models in the sphere of management practices in the field of regional culture, taking into account not only the problem of preserving traditional culture, but also the needs of self-organization of different groups of the population, the formation of their activity and intersubjectivity. The object is regional culture in the context of interaction of heads of cultural and leisure institutions with the population. The subject of the study is the subject-object relations that develop in the field of regional culture management. The aim of the research was to assess the effectiveness of the presented subject-object model of studying regional culture in the field of management, which revealed the mechanisms of typification of cultural experience, the formation of «we-groups» and «common social heritage». Methodology is based on the phenomenological research paradigm, the "Model standard of cultural and leisure institutions», statistical data, unstructured interviews of leaders and authorities of the Kursk region, formation of a detailed view of the daily practices of interaction between leaders and the population in the structure of regional culture. Summary. The subject-object model of studying regional culture allows attributing daily practices of interaction of heads and the population as self-organizing, based on mechanisms of assimilation of traditional culture with intersubjective orientation.

Key words: Regional culture, subject-object relations, cultural and leisure cultural institutions, managers, everyday life.

\section{REFERENCES}

1. Stenograficheskiy otchet o zasedanii Gosudarstvennogo soveta «O gosudarstvennoy podderzhke traditsionnoy narodnoy kultury $v$ Rossii» [Verbatim report of the meeting of the State Council «On state support of traditional folk culture in Russia»]. Available at: http://kremlin.ru/events/president/transcripts/23986 (accessed 10 October 2019).

2. Natsionalny proekt «Kultura»: plany i napravleniya [The national project «Culture»: plans and directions]. Available at: https://www.mkrf.ru/press/news/natsionalnyy_proekt_kultura_plany_i_napravleniya/ (accessed 28 September 2019).

3. Fominykh O.B. Regionalnaya i provintsialnaya kultura: nekotorye kharakteristiki [Regional and provincial culture: some characteristics]. Sbornik nauchnykh trudov «Vremya kultury v regionalnom prostranstve» [Time of culture in the regional space: collection of scientific works edited by D.N. Maslyuzhenko]. Ed. by D.N. Maslyuzhenko. Kurgan, 2010. pp. 74-84. Available at: http://infoculture.rsl.ru/ donArch/home/news/dek/2010/05/2010-05_r_dek-s1.htm (accessed 10 October 2019).

4. Petrova S.I. Cultural systems and their interaction. Innovatsionnoe razvitie, 2017, no. 4 (9), pp. 132-134. In Rus.

5. Karandashov I.V. Regionalism in the contemporary sociocultural context. Gumanitarnye nauchnye issledovaniya, 2016, no. 6. In Rus. Available at: http://human.snauka.ru/ 2016/06/15686 (accessed 27 September 2019).

6. Petrov I.F. Regional culture as a specific form of existence of society. International Journal of Humanities and Natural Sciences, 2018, vol. 7, pp. 24-27. In Rus. Available at: https://cyberleninka.ru/article/n/ regionalnaya-kultura-kak-spetsificheskaya-forma-suschestvovaniya-sotsiuma (accessed 10 October 2019). 
7. Streletskiy V.N. Cultural regionalism: the essence of the concept, problems of study and the system of indicators. Pskovskiy regionologicheskiy zhurnal, 2012, no. 14, pp. 9-21. In Rus.

8. Hettne B. Globalization and the new regionalism: the second great transformation. Globalism and the New Regionalism. Eds. B. Hettne, A. Inotai, O. Sunkel. The New Regionalism. London, Palgrave Macmillan, 1999. pp. 3-24.

9. Schmitt-Egner P. The concept of «region»: theoretical and methodological notes on its reconstruction. European Integration, 2002, vol. 24, no. 3, pp. 179-200.

10. Sehgal S. The Evolution of NAFTA. An Experience in Regionalism. India Quarterly: a Journal of International Affairs, 2010, vol. 66, no. 3, pp. 303-305.

11. Fawcett L., Hurrell A. Regionalism in the world politics: regional organization and international order. Oxford, Oxford University Press, 1995. 342 p.

12. Schutz A. The phenomenology of the social world. London, Heinemann educational books, 1972. 255 p.

13. Berger P.L., Luckmann Th. The social construction of reality: a treatise in the sociology of knowledge. Available at: http://www.perflensburg.se/Berger\%20social-construction-of-reality.pdf (accessed 27 September 2019).

14. Schutz A. On phenomenology and social relations: selected writings. Chicago, University of Chicago Press, 1970., 327 p.

15. Modelny standart deyatelnosti uchrezhdeniya kulturno-dosugovogo tipa Tverskoy oblasti [The model standard of the institution of cultural and leisure type of the Tver region]. Available at: http://reftop.ru/modelenij-standart-deyatelenosti-uchrejdeniya-kuleturno-dosugo.html (accessed 10 October 2019).

16. O vvedenii $v$ deystvie metodicheskikh rekomendatsiy subektam Rossiyskoy Federatsii i organam mestnogo samoupravleniya po razvitiyu seti organizatsiy kultury i obespechennosti naseleniya uslugami organizatsii kultury [On the implementation of methodological recommendations to the subjects of the Russian Federation and local authorities on the development of a network of cultural organizations and the provision of services to cultural organizations for the population]. Rasporyazhenie Ministerstva kultury Rossiyskoy Federatsii ot 02.08.2017 no. R-965 [The order of the Ministry of Culture of the Russian Federation dated 02.08.2017 N P-965]. Available at: http://docs.cntd.ru/document/456084648 (accessed 10 October 2019)

17. Ob utverzhdenii metodicheskikh ukazanii po realizatsii voprosov mestnogo znacheniya v sfere kultury gorodskikh i selskikh poseleniy, munitsipalnykh rayonov i metodicheskikh rekomendatsiy po sozdaniyu usloviy dlya razvitiya mestnogo traditsionnogo narodnogo khudozhestvennogo tvorchestva [On approval of the Guidelines for the implementation of local issues in the field of culture of urban and rural settlements, municipalities and Methodological recommendations on creating conditions for the development of local traditional folk art]. Prikaz Ministerstva kultury i massovykh kommunikatsiy RF ot 25.05.2006 no. 229 [Order of the Ministry of Culture and Mass Communications of the Russian Federation of May 25, 2006 N 229]. Available at: http://base.garant.ru/192873/\#ixzz63MYILa4x (accessed 10 October 2019).

18. Ob utverzhdenii nomenklatury gosudarstvennykh $i$ munitsipalnykh uslug/rabot, vypolnyaemykh organizatsiyami kulturno-dosugovogo tipa Rossiyskyi Federatsii [On approval of the nomenclature of state and municipal services / work performed by organizations of the cultural and leisure type of the Russian Federation]. Rasporyazhenie Ministerstva kultury RF ot 18.09.2009 no. R-6 [Order of the Ministry of Culture of the Russian Federation of September 18, 2009 N P-6]. Available at: http://base.garant.ru/55170135/\#ixzz63Mcvyu6J (accessed 10 October 2019).

19. Ob utverzhdenii normativov minimalnogo resursnogo obespecheniya uslug selskikh uchrezhdeniy kultury (obshchedostupnykh bibliotek i kulturno-dosugovykh uchrezhdeniy) [On approval of the minimum resource requirements for services of rural cultural institutions (public libraries and cultural and leisure institutions)]. Prikaz Ministerstva kultury RF ot 20.02.2008 no. 32 [Order of the Ministry of Culture of the Russian Federation of February 20, 2008 N 32]. Available at: http://docs.cntd.ru/document/902113553 (accessed 10 October 2019).

20. Bezuglova T.V. Novye formy razvitiya uchrezhdeniya kultury. Kompleksnye kulturnye tsentry v selskoy mestnosti [New forms of development of cultural institutions. Integrated cultural centers in rural areas]. Spravochnik rukovoditelya uchrezhdeniya kultury, 2004, no. 9, pp. 64-67.

21. Andriyanova T.V. «Pasport kulturnoy zhizni» regiona kak instrument sravnitelnogo analiza pokazateley [«Passport of cultural life» of the region as a tool for comparative analysis of indicators]. Materialy $V$ mezhdunarodnoy nauchno-prakticheskoy konferentsii. Aktualnye problemy razvitiya chelovecheskogo potentsiala v sovremennom obshchestve [Actual problems of human potential development in modern society: proceedings of the V international scientific and practical conference. Perm, 5-6 December 2018. Perm, Perm State National Research University Publ., 2018. pp. 172-182. Available at: https://elis.psu.ru/node/555431 (accessed 10 October 2019). 
22. O Strategii natsionalnoy bezopasnosti Rossiyskoy Federatsii [On the National Security Strategy of the Russian Federation]. Ukaz Prezidenta RF ot 31.12.2015 no. 683 [Decree of the President of the Russian Federation of December 31, $2015 \mathrm{~N}$ 683]. Available at: http://www.consultant.ru/document/ cons_doc_LAW_191669/(accessed 10 October 2019)

23. O natsionalnykh tselyakh i strategicheskikh zadachakh razvitiya Rossiiskoy Federatsii na period do 2024 goda [On national goals and strategic objectives of the development of the Russian Federation for the period until 2024]. Ukaz Prezidenta Rossiiskou Federatsii ot 07.05.2018 no. 204 [Decree of the President of the Russian Federation of 05/07/2018, No. 204]. Available at: http://kremlin.ru/acts/bank/43027 (accessed 10 October 2019).

24. O meropriyatiyakh po realizatsii gosudarstvennoy sotsialnoy politiki [On measures for the implementation of state social policy]. Ukaz Prezidenta Rossiiskoy Federatsii ot 07.05.2012 № 597. [Decree of the President of the Russian Federation of 07.05. 2012 No. 597]. Available at: http://base.garant.ru/70170950/ (accessed 10 October 2019).

25. Kultura maloy Rodiny [The federal project of the party «United Russia» «Culture of the Small Homeland»]. Available at: https://er.ru/projects/kultura-maloi-rodiny/ (accessed 10 October 2019).

26. Gosudarstvennaya programma Rossiyskoy Federatsii «Razvitie kultury i turizma na 2013-2020 gody» [The state program of the Russian Federation «Development of culture and tourism for 2013-2020»]. Available at: i-razvitie-https://www.russiatourism.ru/contents/deyatelnost/ programmy-i-proekty/gosudarstvennayaprogramma-rossiyskoy-federatsikultury-i-turizma-na-2013-2020-gody/1/ (accessed 10 October 2019).

Received: 14 October 2019. 